\title{
USE OF SILDENAFIL CITRATE IN TREATMENT OF INTRA UTERINE GROWTH RESTRICTION (IUGR)
}

\author{
By \\ Moslem Fayez Ali Korayem, Mofeed Fawzy Mohamed and Noha \\ Mohamed Sabry
}

Department of Obstetrics and Gynecology, Faculty of Medicine Al- Azhar University

Corresponding author: Moslem Fayez Ali Korayem,

E-mail: moslem_korayem987@gmail.com

\begin{abstract}
Background: Sildenafil citrate is a phosphor-diestrase enzyme 5 inhibitor that leads to increasing the cyclic guanosine monophosphate and so enhancing the vasodilator effect of nitric oxide through which it may increase placental perfusion. So, it is used to treat pre-eclampsia.

Objective: To evaluate the efficacy of low dose sildenafil in the treatment of intra uterine growth restriction by estimating fetal biometry and fetal Doppler parameters using trans-abdominal ultrasound.

Patients and methods: This was a case control study carried on 40 pregnant female, at outpatient clinic of Department of Obstetrics and Gynecology at Zagazig General Hospital with intrauterine growth restriction singleton pregnancy. IUGR was diagnosed with ultrasound and fetal Doppler and gestational age ranged from 26 week of gestation to 31 week of gestation according to first day of last menstrual period in regular cycle patients or first trimestric visit ultrasound.

Results: Umbilical artery Pulsitility Index (PI) in study and control groups before and after therapy showing statistically significant decrease in PI in study group compared to control group after therapy. Improvement in cerebroplacental ratio in study group compared to control group after therapy. There was no statistically significant difference between both groups regarding gestational age at delivery. There was a statistically significant difference regarding changes in Amniotic Fluid Index (AFI) in both groups after therapy.
\end{abstract}

Conclusion: The administration of oral sildenafil tablets $(20 \mathrm{mg}$ twice a day) for 6 weeks improved Doppler indices in umbilical artery and cerebroplacental ratio, yet it had no effect on gestational age at neither birth nor birth weight.

Keywords: Sildenafil, Intra Uterine Growth Restriction, IUGR.

\section{INTRODUCTION}

Intrauterine growth restriction (IUGR) is a syndrome characterized by a deficiency of fetal growth compared to the normal standards for the gestational age. IUGR affects approximately 3 to $7 \%$ of all pregnancies. The growth restricted fetus is at increased risk for morbidity and mortality, it is estimated that perinatal mortality is 5-10 times higher in growth restricted fetus than those of the same gestational age and appropriate size (Sharma et al., 2016).

Ultrasound has been used since the mid-1980s as a tool for determining fetal health. A variety of sonographic parameters have been used to screen and diagnose IUGR including fetal biometry, 
fetal body proportions, amniotic fluid volume, subcutaneous tissue thickness and estimated fetal weight (EFW) (Sovio et al., 2015). Abdominal circumference (AC) and estimated fetal weight (EFW) are the most accurate diagnostic measurements to predict SGA (Larciprete et al., 2010).

Fetal growth aberrations, i.e. IUGR are associated with changes in the body proportions as undernourished fetus directs most of its energy to maintain the growth of vital organs, such as the brain and heart, at the expense of the liver, muscle and fat. This results in decreased abdominal and thigh circumference measurements and hence theoretically increased $\mathrm{HC} / \mathrm{AC}, \mathrm{FL} / \mathrm{AC}$ and FL/TC ratios. However the studies on first two ratios have yielded controversial findings (Dacaj et al., 2016).

Sildenafil citrate is an oral therapy that was first described for the treatment of erectile dysfunction. Sildenafil is a selective inhibitor of cGMP-specific PDE5. Sildenafil citrate was the first PDE-5 inhibitor approved by the United States Food and Drug Administration (FDA). The mechanism of action for the PDE-5 inhibitors involves increased tissue levels of cGMP, which causes smooth muscle relaxation and vasodilatation. The recent advancing clinical studies suggest some very promising new applications of PDE5 inhibitors, far beyond their urological scope (Hatzimouratidis, 2010).

In human, the use of sildenafil citrate in some pregnancy-related disorders as preeclampsia (PET) and IUGR revealed encouraging results (El-Sayed et al., 2018).
The aim of this study was to evaluate the efficacy of low dose sildenafil in the treatment of intra uterine growth restriction by estimating fetal biometry and fetal doppler parameters using transabdominal ultrasound.

\section{PATIENTS AND METHODS}

This study had been conducted at outpatient clinic of Department of Obstetrics and Gynecology at Zagazig General Hospital from December 2019 to August 2020. This was a case control study that included 40 pregnant women diagnosed as IUGR.

Ethical Consideration: Study protocol had been submitted for approval by ethical committee of Al-Azhar University. Informed written consent had been obtained from each participant sharing in the study. Confidentiality and personal privacy had been respected in all levels of the study.

Inclusion criteria: Pregnant women aged from 21 to 45years old, pregnant women with singleton pregnancy, IUGR as diagnosed with ultrasound and fetal Doppler, and pregnant women at gestational age from 26 week of gestation to 31 week of gestation according to first day of last menstrual period in regular cycle patients or first trimester visit ultrasound.

Exclusion criteria: Pregnant women $<21$ or $>45$ years old, pregnant women with multiple pregnancies, pregnant women with congenital fetal malformations, pregnant women with premature rupture of membranes, pregnant women using any vasodilator drugs in treatment of preconceptional medical diseases, maternal vascular diseases that affect fetal 
Doppler as autoimmune diseases, pregnant women who were smokers or alcohol abusers, and pregnant women who developed an urgent delivery during follow up.

Patients were divided into two equal groups: Group I (Case group) have received $20 \mathrm{mg}$ of Sildenafil Citrate twice daily, and Group II (Control group) have not received the drug.

\section{Patients were subjected to:}

Complete history taking: Personal history, menstrual history, obstetric history, present history, family history, history of allergy to any medication including sildenafil citrate and surgical history of operations.

Examination: General examination and Abdominal and local clinical examination.

Investigations: Complete blood count. Coagulation profile. Liver and kidney function tests. Complete urine analysis. Random blood sugar. Others, e.g. protein creatinine ratio.

Ultrasound: Trans-abdominal ultrasound examination by a GE Voluson 730 Proultrasound machine with a $3.5 \mathrm{MHz}$ abdominal probe. Sonographic examinations had been performed by only one sonographer. All of the sonographic examinations will be recorded digitally. Women had been scanned weekly to; Correlate gestational age according to first day of last menstrual period in regular cycle patients or first trimester visit ultrasound and current gestational age at time of first visit by ultrasound. Measure expected fetal body weight. Fetal biometry Abdominal Circumference (AC), Bi Parietal Diameter (BPD), Head Circumference (HC), Femur Length(FL),
Amniotic Fluid Index (AFI). Fetal Doppler ultrasound over umbilical artery and middle cerebral artery.

Doppler flowmetry: For umbilical artery and middle cerebral artery. Distribution of blood flow in the fetus was measured by $\mathrm{C} / \mathrm{U}(\mathrm{C}=$ middle cerebral artery resistance index, $\mathrm{U}=$ umbilical artery resistivity index) which is more than 1.1 throughout the normal pregnancy. Ultrasonography and Doppler were done at time of first visit and repeated weekly after initiation of treatment and then followed-up regularly until 31 weeks of gestation.

Outcome measures of the study as following: Umbilical artery Doppler: Pulsitility Index (P.I), Resistivity Index (R.I). Middle cerebral artery Doppler (P.I, R.I). Fetal biometry: Abdominal Circumference (AC), Bi Parietal Diameter (BPD), Head Circumference (HC), Femur Length (FL), Amniotic fluid Index (AFI).

\section{Statistical Analysis:}

Data collected throughout history, basic clinical examination, laboratory investigations and outcome measures coded, entered and analyzed using Microsoft Excel software. Data were then imported into Statistical Package for the Social Sciences (SPSS version 20.0) software for analysis. According to the type of data quantitative continues group were represented by mean \pm SD and range, the following tests were used to test differences for significance. Differences between quantitative independent groups by $\mathrm{t}$ test or Mann Whitney, paired t test was used to compare before and after date for the same group. $\mathrm{P}$ value was set at $<0.05$ for significant results. 


\section{RESULTS}

There was no significant difference between groups regarding age. The mean \pm SD ages of patients and controls were $(28.4 \pm 6.8)$ years and $(28.6 \pm 6.4)$ years, respectively. Also, there was no significant difference between groups regarding BMI. The mean $\pm \mathrm{SD}$ BMI of Case and controls were $(25.4 \pm 2.4)$ and $(25.3 \pm 2.3)$, respectively. So patient and control group were age and BMI matched (Table 1).

Table (1): Demographic and baseline clinical characteristics of the study groups.

\begin{tabular}{|l|c|c|c|}
\hline \multicolumn{1}{|c|}{ Groups } & $\begin{array}{c}\text { Case } \\
(\mathbf{n = 2 0})\end{array}$ & $\begin{array}{c}\text { Control } \\
(\mathbf{n = 2 0})\end{array}$ & P value \\
\hline $\begin{array}{l}\text { Age (yrs.) } \\
\text { Mean } \pm \text { SD }\end{array}$ & $28.4 \pm 6.8$ & $28.6 \pm 6.4$ & $>0.05$ \\
\hline $\begin{array}{l}\text { Weight (kg) } \\
\text { Mean } \pm \text { SD }\end{array}$ & $70.3 \pm 5.12$ & $70.90 \pm 5.09$ & $>0.05$ \\
\hline $\begin{array}{l}\text { Height (m) } \\
\text { Mean } \pm \text { SD }\end{array}$ & $1.66 \pm 0.31$ & $1.64 \pm 0.32$ & $>0.05$ \\
\hline $\begin{array}{l}\text { BMI(kg/m3) } \\
\text { Mean } \pm \text { SD }\end{array}$ & $25.4 \pm 2.4$ & $25.3 \pm 2.3$ & $>0.05$ \\
\hline
\end{tabular}

Umbilical artery UA S/D showed a statistically significant decrease in UA $\mathrm{S} / \mathrm{D}$ in study group compared to control group after therapy. Umbilical artery PI showed a statistically significant decrease in PI in study group compared to control group after therapy. Middle cerebral artery PI before and after therapy showed a statistically significant difference (Table 2). 
Table (2): Umbilical artery UA S/D ratio, umbilical artery P.I and Middle cerebral artery (MCA) PI in study and control groups before and after therapy

\begin{tabular}{|c|c|c|c|}
\hline $\begin{array}{ll} & \text { Groups } \\
\text { Parameters } & \end{array}$ & $\begin{array}{c}\text { Control } \\
(n=20)\end{array}$ & $\begin{array}{c}\text { Case } \\
(\mathbf{n}=20)\end{array}$ & $\mathbf{P}$ \\
\hline \multicolumn{4}{|l|}{ UA S/D: } \\
\hline \multicolumn{4}{|l|}{ Before } \\
\hline Min. - Max. & $2.10-1.80$ & $2.30-4.10$ & \multirow{2}{*}{$>0.05$} \\
\hline Mean \pm SD & $3.1 \pm 0.58$ & $3.41 \pm 0.55$ & \\
\hline \multicolumn{4}{|l|}{ After } \\
\hline Min. - Max. & $2.30-3.70$ & $2.60-3.70$ & \multirow{2}{*}{$>0.05$} \\
\hline Mean \pm SD & $3.11 \pm 0.65$ & $3.02 \pm 0.33$ & \\
\hline $\mathrm{p}_{1}$ & $>0.05$ & $0.025^{*}$ & \\
\hline \multicolumn{4}{|l|}{ UA PI: } \\
\hline \multicolumn{4}{|l|}{ Before } \\
\hline Min. - Max. & $0.92-1.51$ & $0.91-1.40$ & \multirow{2}{*}{$>0.05$} \\
\hline Mean \pm SD. & $1.03 \pm 0.14$ & $1.05 \pm 0.11$ & \\
\hline \multicolumn{4}{|l|}{ After } \\
\hline Min. - Max. & $0.86-1.20$ & $0.90-1.50$ & \multirow{2}{*}{$>0.006$} \\
\hline Mean \pm SD. & $1.04 \pm 0.15$ & $1.17 \pm 0.13$ & \\
\hline $\mathrm{p}_{1}$ & $>0.05$ & $0.012^{*}$ & \\
\hline \multicolumn{4}{|l|}{ MCA PI: } \\
\hline \multicolumn{4}{|l|}{ Before } \\
\hline Min. - Max. & $1.3-2.50$ & $1.2-2.3$ & \multirow{2}{*}{$>0.05$} \\
\hline Mean \pm SD. & $1.80 \pm 0.31$ & $1.65 \pm 0.42$ & \\
\hline \multicolumn{4}{|l|}{ After } \\
\hline Min. - Max. & $1.85-2.30$ & $1.75-2.60$ & \multirow{2}{*}{$<0.05$} \\
\hline Mean \pm SD & $2.01 \pm 0.15$ & $2.11 \pm 0.21$ & \\
\hline $\mathrm{p}_{1}$ & $>0.05$ & $0.01^{*}$ & \\
\hline
\end{tabular}

There was an improvement in cerebro placental ratio in study group compared to control group after therapy (Table 3).

Table (3): Cerebro placental ratio (CPR) in study group compared to control group after therapy

\begin{tabular}{|c|c|c|c|}
\hline $\begin{array}{ll}\text { CPR } & \text { Groups } \\
\end{array}$ & $\begin{array}{l}\text { Control } \\
(\mathbf{n}=20)\end{array}$ & $\begin{array}{c}\text { Case } \\
(\mathbf{n}=20)\end{array}$ & $\mathbf{P}$ \\
\hline \multicolumn{4}{|l|}{ Before } \\
\hline Min. - Max. & $1.46-2.58$ & $1.38-2.67$ & \multirow{2}{*}{$>0.05$} \\
\hline Mean \pm SD. & $1.97 \pm 0.30$ & $2.01 \pm 0.34$ & \\
\hline \multicolumn{4}{|l|}{ After } \\
\hline Min. - Max. & $1.49-2.66$ & $1.01-2.0$ & \multirow{2}{*}{$0.01^{*}$} \\
\hline Mean \pm SD. & $1.94 \pm 0.34$ & $1.42 \pm 0.31$ & \\
\hline $\mathrm{p}_{1}$ & $>0.05$ & $<0.01^{*}$ & \\
\hline
\end{tabular}

There was a statistically significant difference regarding rate of increase of estimated fetal weight per week in both study and control groups (Table 4). 
Table (4): Rate of increase of estimated fetal weight per week in both study and control groups

\begin{tabular}{|l|c|c|c|c|}
\hline EFW/W (g) & $\begin{array}{c}\text { Cases } \\
(\mathbf{n = 2 0})\end{array}$ & Control $(\mathbf{n = 2 0})$ & U & P \\
\hline Min. - Max. & $63.1-126.60$ & $66.1-116.0$ & 122.5 & 0.031 \\
\hline Mean \pm SD. & $98.16 \pm 30.2$ & $90.20 \pm 19.3$ & 0.3 \\
\hline
\end{tabular}

The $U$ value was 122.5, and the critical value of $U$ at $P<0.05$ was 127 .

Regarding changes in AFI in both groups after therapy, there was a and after treatment (Table 5).

Table (5): Regarding changes in amniotic fluid index (AFI) in both groups after therapy

\begin{tabular}{|c|c|c|c|c|c|}
\hline $\begin{array}{l}\text { Groups } \\
\text { AFI }(\mathrm{cm})\end{array}$ & $\begin{array}{l}\text { Cases } \\
(\mathbf{n}=20)\end{array}$ & $\begin{array}{c}\text { Control } \\
(\mathrm{n}=20)\end{array}$ & $\mathbf{W}$ & $\mathbf{U}$ & $\mathbf{P}$ \\
\hline \multicolumn{6}{|l|}{ Pre-treatment } \\
\hline Min. - Max. & $3.0-15.0$ & $5.0-20.0$ & \multirow{2}{*}{71.5} & \multirow{2}{*}{175} & \multirow{2}{*}{$>0.05$} \\
\hline Mean \pm SD & $5.50 \pm 3.08$ & $6.93 \pm 3.79$ & & & \\
\hline \multicolumn{6}{|l|}{ Post treatment } \\
\hline Min. - Max. & $5.0-13.0$ & $3.0-17.0$ & \multirow{2}{*}{47} & \multirow{2}{*}{123} & \multirow{2}{*}{0.03} \\
\hline Mean \pm SD. & $6.07 \pm 2.09$ & $6.03 \pm 3.33$ & & & \\
\hline $\mathrm{p}_{1}$ & 0.024 & $>0.05$ & & & \\
\hline
\end{tabular}

Pre-treatment *the $U$ value was 175 . The critical value of $U$ at $P<0.05$ was 127.

$*$ The value of Wilcoxon signed rank test was 71.5. The critical value of Wilcoxon signed rank test at $\mathrm{N}=20$ $(\mathrm{P}<0.05)$ is 52 .

Post treatment*the $\mathrm{U}$ value was 123 . The critical value of $\mathrm{U}$ at $\mathrm{P}<0.05$ was 127 .

$*$ The value of Wilcoxon signed rank test was 47 . The critical value of Wilcoxon signed rank test at $\mathrm{N}=20$ $(\mathrm{P}<0.05)$ wes 52.

\section{DISCUSSION}

The present study showed that there was no significant difference between groups regarding age. This was in agreement with study conducted by Mohammed et al. (2017).

Regarding BMI, there was no significant difference between groups. This was in agreement with Mohammed et al. (2017).

This study showed that umbilical artery UA S/D in study and control groups before and after therapy with a statistically significant decrease in UA S/D ratio and umbilical artery PI. According to middle cerebral artery this study showed that middle cerebral artery PI increased after sildenafil administration in case group and showed a statistically significant difference between two groups.

According to EFBW, this study showed that there was a statistically significant difference regarding rate of increase in abdominal circumference and EFBW in both groups after therapy. Moreover, this study showed improvement in cerebro placental ratio in case group compared to control group after therapy.

Maged et al. (2018) showed a statistically significant difference in the mean birth weight at delivery and neonatal 
admission to the newborn nursery in sildenafil group.

Abdelshafy et al. (2019) showed a significant improvement in umbilical and middle cerebral artery indices after sildenafil administration. This difference became evident after 3 weeks of gestation from sildenafil administration mainly after 33 weeks of pregnancy where mean umbilical artery pulsatility index (UAPI) significantly decreased in the sildenafil group in comparison with the placebo group. Regarding the middle cerebral artery velocity indices, there was significant increase in mean MCA pulsatility index (PI) after sildenafil administration in comparison with the placebo group at term. Also, in sildenafil group, there was a significantly higher mean neonatal birth weight. There was a significantly higher mean gestational age at delivery in women in sildenafil group, whereas it was lower in the placebo group.

Maher et al. (2017) concluded that a significant difference in the rate of remaining undelivered was detected from 3 weeks onward for those allocated to sildenafil.

Vigil-De Gracia and Ludmir (2016) found that resistance to blood flow in the uterine and umbilical arteries was significantly lower in patients treated with sildenafil citrate. These were with reduction in resistance to blood flow in the uteroplacental and fetoplacental circulations.

Khan et al. (2017) showed that randomized trial with 37 patients in study group who were administered Sildenafil $25 \mathrm{mg}$ TID and 56 patients in control group who were administered a similar placebo. Velocimetry indices in umbilical artery and middle cerebral artery were calculated at eligibility and one week post initiation of intervention. Differences in Sildenafil treated and Sildenafil naive. Sildenafil treated fetuses have significantly higher decrease in RI. In umbilical artery compared to control group. Middle cerebral artery velocimetry showed a higher increase in RI in study vs. control group from eligibility to determination of effect. A significantly higher increase was also seen at determination in study group compared to control group. Sildenafil appeared to significantly normalize ultrasound doppler velocimetry indices in foetuses affectted with late onset restriction.

Trapani et al. (2016) conducted a double-blind, placebo-controlled trial to evaluate the effects of sildenafil citrate on Doppler velocity waveforms of umbilical (UA) and fetal middle cerebral (MCA) arteries in pregnancies with intrauterine growth restriction (IUGR). They compared pulsatility index (PI) of UA and fetal MCA before and after application of oral sildenafil citrate $(50 \mathrm{mg})$ or placebo. There was a significant reduction in UAPI, also observed for sildenafil citrate $(18.2 \%)$. No changes in Doppler velocimetry were observed in the placebo group and no significant change in MCAPI was observed in any group.

Regarding changes in AFI in both groups, this study showed a statistically significant difference before and after treatment in case group.

Khodry et al. (2020) showed an insignificance difference in EFBW in both groups, but AFI was significant increase in group which administrated sildenafil. 
This insignificance may be due to short time of follow up.

El-Sayed et al. (2018) found that Umbilical artery $S / D$ ratio has no significant difference. The difference may be due to their gestational age sample was 24 week and more.

Sharp et al. (2018) Concluded that Sildenafil did not prolong pregnancy or improve pregnancy outcomes in severe early-onset fetal growth restriction. Moreover they reported a possibility that the $25 \mathrm{mg}$ dose three times daily might have a deleterious effect on blood flow in the ductus venosus particularly in fetuses with absent or reversed end-diastolic flow in the umbilical artery. That may be different from results of this study due to early onset of administration of sildenafil and prolonged administration in some cases till delivery, and change dose 3 times per day not two times. These results may be due to studying only early onset of IUGR (22week of gestation).

Mohammed et al. (2017) Conclude that the administration of oral sildenafil tablets $20 \mathrm{mg}$ twice a day for 6 weeks improved Doppler indices in umbilical artery and cerebroplacental ratio, yet it had no effect on birth weight. The difference may be due to small sample size in this study.

\section{CONCLUSION}

The administration of oral sildenafil tablets (20 mg twice a day) for 6 weeks improved Doppler indices in umbilical artery and cerebroplacental ratio, yet it had no effect on gestational age at neither birth nor birth weight.

\section{REFERENCES}

1. Abdelshafy A, Abdullah KI and Ashoush S. (2019): The role of sildenafil citrate in the treatment of fetal growth restriction: a randomized controlled trial. International Journal of Reproduction, Contraception, Obstetrics and Gynecology, 8(5): 1840-45.

2. Dacaj R, Izetbegovic S, Stojkanovic G and Gjocaj C (2016): Hepato-Cephalic index as a predictor of Intrauterine Growth Restriction. Acta Informatica Medica., 24(1), 12.

3. El-Sayed MA, Saleh SA, Maher MA and Bayome A. (2018): Effect of sildenafil citrate on uteroplacental perfusion Doppler indices in growth-restricted fetuses. Menoufia Medical Journal, 31(1): 31-35.

4. Hatzimouratidis K. (2010): Sildenafil in the treatment of erectile dysfunction: an overview of the clinical evidence. Clin Interv Aging., 1(4): 403-414.

5. Khan MI, Yasmeen $A$ and Swetha $M$. (2017): Sildenafil Citrate Improves Ultrasound Doppler Velocimetry Indices in Foetal Growth Restriction-A Randomised Controlled Trial At A Tertiary Care Teaching Hospital in South India. IOSR Journal of Dental and Medical Sciences (IOSR-JDMS), 16(2): 86-92.

6. Khodry MM, Taha SA and Abdelghany AM. (2020): Use of Sildenafil Citrate in Woman with Hypertensive Disorders during Pregnancy. SVU-International Journal of Medical Sciences, 4(1):15-19.

7. Larciprete $\mathbf{G}$, Valensise $\mathbf{H}$ and Di Pierro G. (2010): Intrauterine growth restriction and fetal body composition. Ultrasound in Obstetrics and Gynecology: The Official Journal of the International Society of Ultrasound in Obstetrics and Gynecology, 26(3): 258-262.

8. Maged M, Wageh A and Shams M. (2018): Use of sildenafil citrate in cases of intrauterine growth restriction (IUGR); a prospective trial. Taiwanese Journal of Obstetrics and Gynecology, 57(4): 483-486.

9. Maher MA, Sayyed T M and Elkhouly N. (2017): Sildenafil citrate therapy for oligohydramnios: a randomized controlled trial. Obstetrics \& Gynecology, 129(4): 615620. 
10. Mohammed EE, Alashkar OS, Abdeldayem TM and Mohammed SA. (2017): The use of low dose sildenafil citrate in cases of intrauterine growth restriction. Clin Obstet Gynecol Reprod Med., 3(4): 1-5.

11. Sharma D, Shastri $S$ and Sharma P. (2016): Intrauterine growth restriction: antenatal and postnatal aspects. SAGE Journal, 10: 40-45.

12. Sharp A, Cornforth C, Jackson $R$ and Turne M. (2018): Maternal sildenafil for severe fetal growth restriction (STRIDER): a multicentre, randomised, placebo-controlled, double-blind trial. The Lancet Child \& Adolescent Health, 2(2): 93-102.

13. Sovio U, White IR, Dacey A, Pasupathy D and Smith GCS. (2015): Screening for fetal growth restriction with universal third trimester ultrasonography in nulliparous women in the Pregnancy Outcome Prediction (POP) study: a prospective cohort study. The Lancet, 386(10008): 2089-2097.

14. Trapani A, Gonçalves LF and Trapani TF. (2016): Comparison between transdermal nitroglycerin and sildenafil citrate in intrauterine growth restriction: effects on uterine, umbilical and fetal middle cerebral artery pulsatility indices. Ultrasound in Obstetrics \& Gynecology, 48(1): 61-65.

15. Vigil-De Gracia $P$ and Ludmir J. (2016): Perinatal and Hemodynamic Evaluation of Sildenafil Citrate for Preeclampsia Treatment: A Randomized Controlled Trial. Obstetrics \& Gynecology, 128(5): 1181-1182. 


\section{إستخدام عقار سترات السيلدينافيل في علاج حالات تأخر نمو

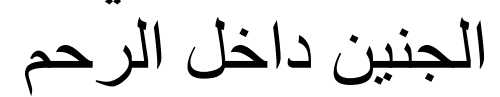

\section{مسلم فايز علي كُريم، مفيد فوزي محمد، نهى محمد صبري}

قسم التوليد وأمراض النساء، كلية الطب، جامعة الأزهر

E-mail: moslem_korayem987@gmail.com

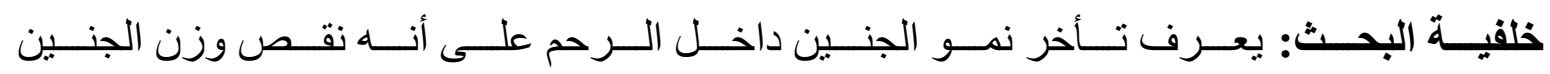

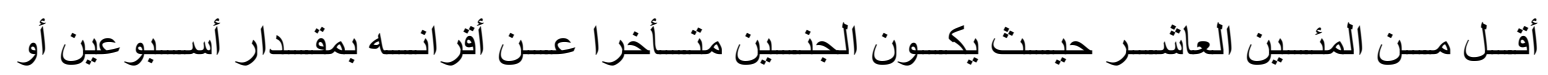

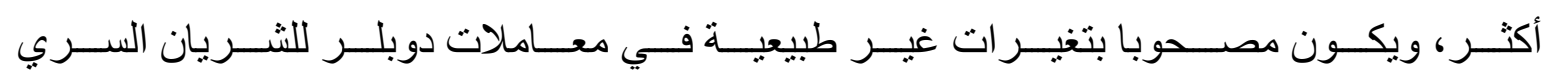

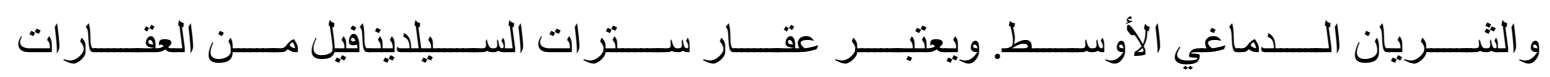

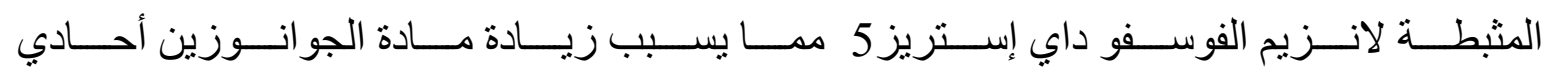

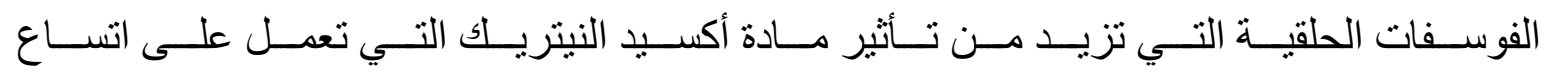

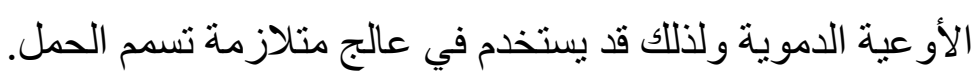

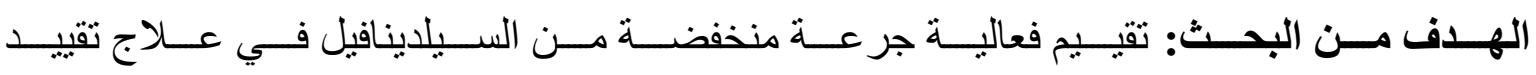

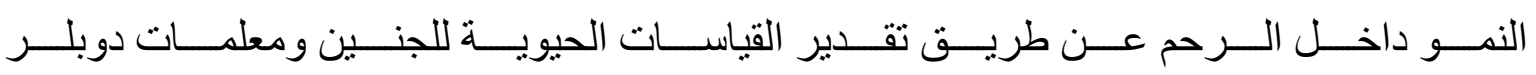
الجنين باستخدام الموجات فوق الصوتية عبر البطن.

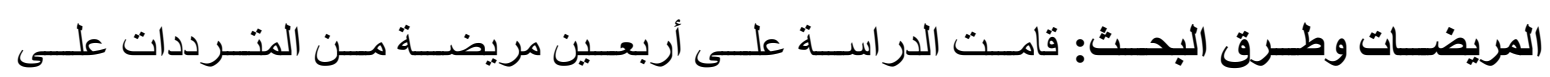

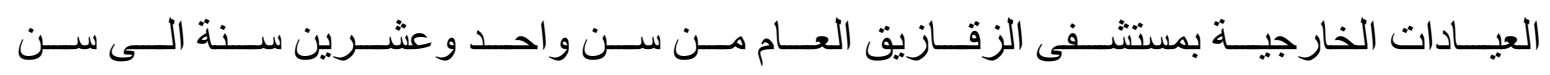

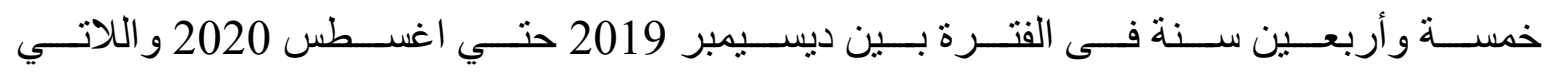

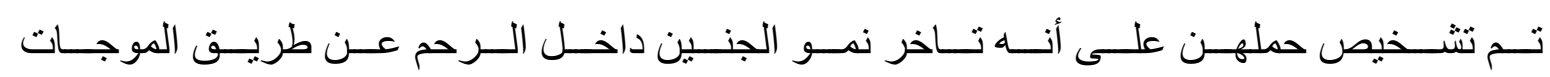

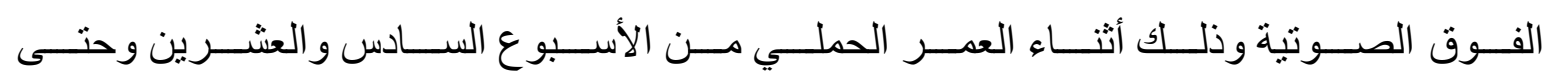

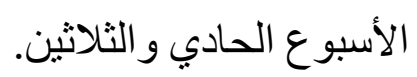

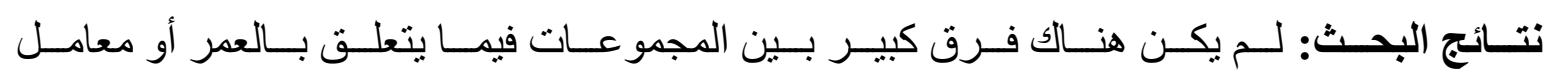

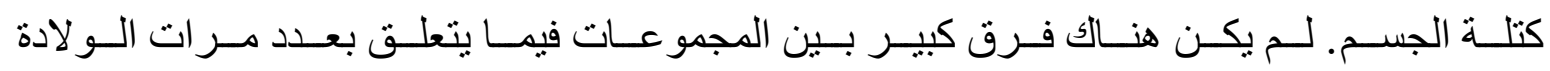

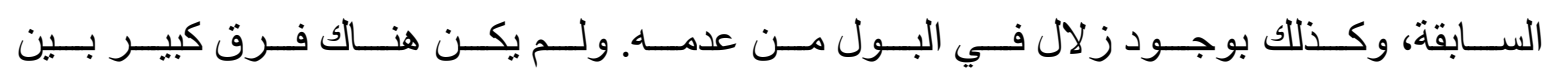

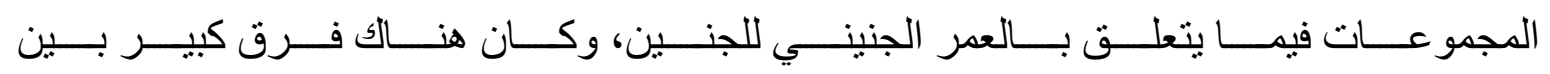

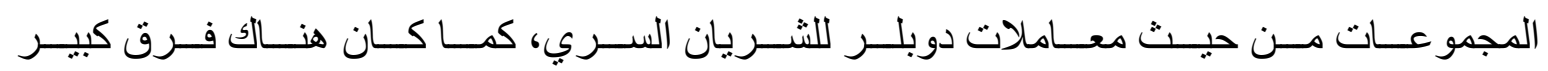




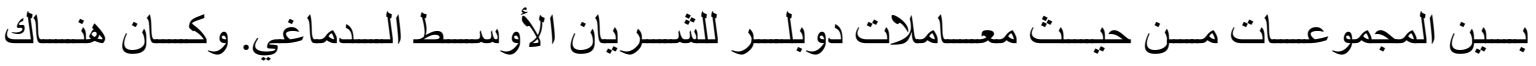

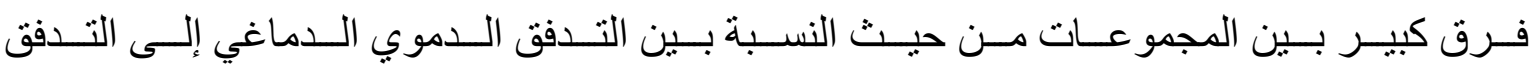

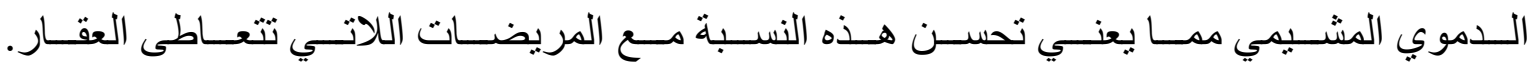

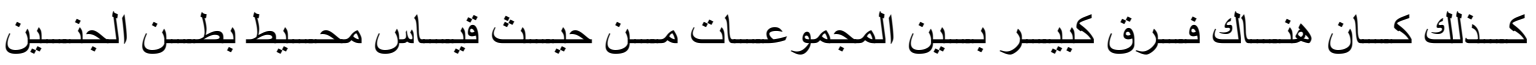

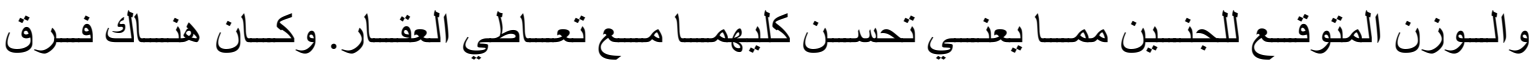

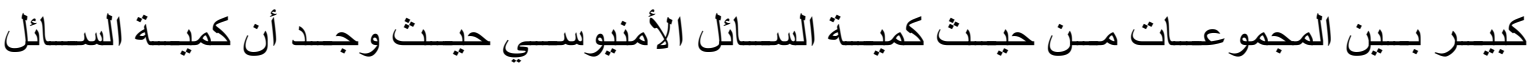
الأمنيوسي تتحسن مع تعاطي العقار.

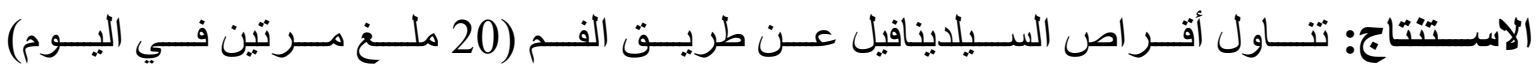

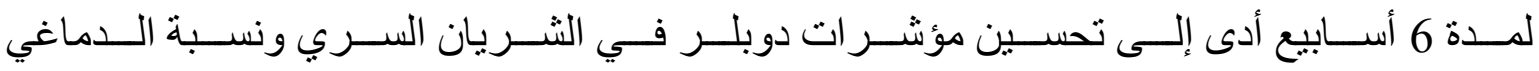
الاماغي، إلا أنه لم يكن لله تأثير على عمر الحمل عند الولادة أو وزن الو لادة. الكلمات الدالة: سيلدينافيل، تقييد النمو داخل الرحم، تأخر النمو داخل الرحم. 